\title{
Bay of Bengal Monsoon Experiment (BOBMEX) - A component of the Indian Climate Research Programme (ICRP)
}

\author{
D R SIKKA ${ }^{1}$ and P SANJEEVA RAO ${ }^{2}$ \\ ${ }_{4}^{1} 0$ Mausam Vihar, New Delhi 110051 , India \\ ${ }^{2}$ Department of Science and Technology, New Delhi 110 016, India.
}

The Indian Climate Research Programme (ICRP) focuses on the study of climate variability and its impact on agriculture. To address the role of the Bay of Bengal in monsoon variability, a process study was organised during July-August 1999, deploying research ships, buoys, INSAT, coastal radar and conventional observational systems to collect information about the coupled ocean-atmosphere system over the warm waters of the Bay of Bengal. The paper gives the background of the ICRP and the organisation and implementation of the Bay of Bengal Monsoon Experiment (BOBMEX) in its field phase.

\section{Introduction}

Climate variability has become an important topic of scientific pursuit during the last two decades or so. The economy of a nation is intimately linked with its climate-resource. Any short-term (within a season) or long-term (inter-annual and decadal scales) fluctuations in the climate have important impacts on the progress of a nation, particularly so in a developing economy. India's economy has been traditionally known to be a gamble on the monsoon. Therefore a deeper understanding of the monsoon variability on different time-scales is expected to pave the way for better predictions on the performance of rains over India during the summer monsoon season. The Indian Climate Research Programme (ICRP), as formulated in its Science Plan (DST, 1996), is a multi-agency programme which is focussed on the following major objectives:

- Understanding the physical processes responsible for climate variability on sub-seasonal, seasonal, interannual and decadal time-scales of the monsoon, the oceans (especially the Indian seas and the equatorial Indian Ocean) and the coupled atmosphere-ocean-land system.
- Study of the space-time variation of the monsoon from sub-seasonal, interannual to decadal scales for assessing the feasibility for climate prediction and development of methods for prediction.

- Study of change in climate and its variability on centennial and longer time scales generated by natural and anthropogenic factors.

- Investigation of the links between climate variability and critical resources such as agricultural productivity to provide a basis for deriving agricultural strategies for maximising the sustainable yield in the face of climate variability, and for realistic assessment of impact of climate change.

ICRP addresses the above foci in three components viz.,

- Monsoon Variability (MONVAR),

- Past Climates and Climate Change (PCCC) and

- Climate and Agriculture (CLIMAG).

Several departments of the Government of India (Department of Science and Technology (DST), Department of Ocean Development (DOD), Defence Research and Development Organisation (DRDO), Department of Space (DOS), India Meteorological Department (IMD), Council of Scientific and Industrial

Keywords. Monsoon; climate variability; Bay of Bengal; ocean-atmosphere coupling. 
Research (CSIR), Ministry of Environment and Forests (MoEF), Indian Council of Agricultural Research (ICAR) and their agencies and autonomous research organisations under their control as well as universities and institutions like Indian Institute of Science (IISc), Indian Institute of Technology (IIT), Delhi are participating in the promotion and implementation of the ICRP.

The programme MONVAR addresses questions relating to variability of monsoon, oceans and the coupled system. It has four process-oriented sub-programmes viz. Bay of Bengal Monsoon (BOBMON), Arabian Sea Monsoon (ARMON), Continental Tropical Convergence Zone (CTCZ) and Circulation, Hydrology and Thermodynamics of North Indian Ocean (CHATNI). These sub-programmes are to be carried out in stages over the next several years to obtain detailed data for better understanding of the coupled processes involved in monsoon variability within the ambit of the coupled land-ocean-atmosphere system. Within the BOBMON sub-programme the processes to be studied include:

- Heat and freshwater balance of the Bay of Bengal,

- Coupling between the mixed layers of the atmosphere and the ocean,

- Convective cloud systems over the Bay on different space-time scales,

- Structure of meso-scale convection,

- Role of low-frequency waves in the circulation over the Bay of Bengal.

\section{Bay of Bengal Monsoon Experiment (BOBMEX)}

To address the problems linked with the fluctuations of the Bay of Bengal Monsoon during the summer monsoon season (June-September), a multi-pronged approach (viz., monitoring by conventional atmospheric networks with relevant enhancement, recently installed Met-Ocean Buoy network of DOD, weather satellites, etc.) is necessary. The intensive field phase observational component known as Bay of Bengal Monsoon Experiment (BOBMEX) was formulated for better understanding of monsoon-related processes with the following broad objectives.

- Study of the vertical stability of the atmosphere during different phases of organised convection,

- Study of variability of upper ocean currents in relation to changing wind and thermohaline circulation,

- Study of the surface fluxes and atmospheric and oceanic boundary layer characteristics during different phases of convection, and

- Air-sea coupling.

BOBMEX is planned to be carried out as a well coordinated multi-agency project with the nodal agency being DST. Several committees (Inter Departmental Committee for ICRP, Standing Committee on Earth System Sciences of DST, Project Advisory and Monitoring Committee for Monsoon and Tropical Climate (MONTCLIM) and Indian Climate Research Programme (ICRP), Working Group on AtmosphereOcean Field Experiments under ICRP, Committee on Atmospheric and Oceanographic Instruments etc.) held science meetings during 1997-1999 to plan and implement the BOBMEX. It had been decided in early 1998 that prior to the full field operation of BOBMEX, to be undertaken in July-August 1999, a short duration Pilot experiment (BOBMEX-Pilot) be carried out in 1998. This was required to test the field readiness of different facilities (research ships, metocean buoy, conventional systems, specially acquired physical oceanography and meteorological instruments to be used on board research ship, etc.). BOBMEX was designed exclusively for the first time jointly by the ocean-atmosphere science community in India. This was considered to be very relevant as BOBMEX was focussed on the study of the coupled ocean-atmosphere system, which is important for the variability of the Indian monsoon.

\section{Implementation of BOBMEX-Pilot}

The special observing systems deployed for the BOBMEX-Pilot experiment were the oceanographic research vessel Sagar Kanya (ORV-SK) and the Metocean buoys in the Bay of Bengal and the India Meteorological Department (IMD) conventional observing systems over the Bay of Bengal islands and east coast of India. Measurements on board ORV-SK included deployment of several advanced sensors and instruments. The main objectives of the BOBMEX Pilot were:

- To try out the objectives of the BOBMEX on a smaller scale, in order to test the equipment/systems required for meeting the objectives of BOBMEX, develop modalities for archiving the data and their dissemination and also identify problem areas.

- To obtain high quality data during the experiment so as to be useful in understanding inter-annual variability when combined with data from the past and future field studies and also to help in the design and proper implementation of the main BOBMEX in 1999.

The BOBMEX-Pilot was successfully carried out during October-November 1998. ORV Sagar Kanya sailed from its base in Goa on October 23rd and reached Tuticorin on November 12th, thus, providing nearly three weeks of observations. The first stationary position was taken by the vessel near $7^{\circ} \mathrm{N} 87^{\circ} \mathrm{E}$ for two days on October 30th and 31st, 1998. The second and third stationary positions were taken by the vessel 
on 2nd-3rd November 1998 near $10^{\circ} \mathrm{N} 87^{\circ} \mathrm{E}$ and on 5 th November near $13^{\circ} \mathrm{N} 87^{\circ} \mathrm{E}$. Thus, the three stationary positions were along a meridional direction along $87^{\circ} \mathrm{E}$ beginning in near-equatorial warm waters at $7^{\circ} \mathrm{N}$ and ending at $13^{\circ} \mathrm{N}$. This was the zone where organised convection associated with the withdrawing southwest monsoon was located. Fluctuations in its intensity were observed with the formation/passage of cyclonic disturbances.

The atmospheric component of the observations on ORV Sagar Kanya was managed by the Centre for Atmospheric and Ocean Studies of the Indian Institute of Science, Bangalore while the oceanic component was managed by the National Institute of Oceanography, Goa. Data were collected on various atmospheric, ocean-atmosphere coupled and oceanic parameters. Some of the observations such as the air-sea (fast and slow response) fluxes parameters, sea surface temperature (SST) using infra-red thermometer, outgoing longwave radiation (OLR) and incoming solar radiation and high resolution temperature and humidity soundings of the atmosphere were done for the first time. Besides, oceanographic observations on CTD and currents using VM-ADC probe were also collected.

The period of the experiment witnessed two active weather disturbances in the area of the experiment - a cyclonic storm and a low pressure area. The data collected were distributed among participating scientists and agencies. A workshop was organised by the DST to discuss the results of the BOBMEX-Pilot at the IIT, New Delhi on 23rd April 1999 during which 12 papers containing the preliminary results utilising the data collected during the pilot experiment were presented. The major results which emerged from these studies were:

- Significant fluctuations in $\operatorname{SST}\left(>1.0^{\circ} \mathrm{C}\right)$ during the experiment as a consequence of active synoptic weather activity.

- Fluctuations of the atmospheric boundary layer (ABL) in response to synoptic weather disturbances and simulation of the ABL.

- Spatial distribution of ocean mixed layer from nearequatorial to central Bay of Bengal.

- Role of northward advective processes on the upper ocean thermodynamics of the south Bay of Bengal.

- Net heat loss over the Bay of Bengal.

- Air-sea exchange processes including exchange of Dimethyl Sulphide (DMS).

The results of the detailed analysis of the observations during the pilot experiment are presented by different authors in this issue.

\section{Implementation of BOBMEX-Main}

The main phase of the BOBMEX-1999 was also successfully carried out from 16th July - 31st August
1999 for a period of nearly 45 days. Two research Vessels, (ORV Sagar Kanya of Antarctica Study Centre, DOD, Goa and R V Sagar Dhwani of Naval Physical Oceanographic Laboratory, Cochin) and 2 deep ocean buoys in the Bay of Bengal deployed by the National Institute of Ocean Technology (NIOT) were used as special observing platforms. The IMD provided the requisite observational support from the coastal network (Calcutta, Bhubaneswar, Vishakapatnam, Machilipatnam, Chennai, Karaikal and Portblair) of conventional meteorological observations such as radiosonde, radar and INSAT imageries, during the experimental period. The IMD and National Centre for Medium Range Weather Forecasting (NCMRWF), New Delhi provided the synoptic weather and model output products to the ships as weather advisories. The BOBMEX Operations Science Team (BOST) provided the necessary guidance in identifying the intensive observational periods. All these activities during the BOBMEX main experiment were co-ordinated by the BOBMEX Operations Centre at IMD, Mausam Bhawan, New Delhi. About 80 scientists working in multi-disciplinary subjects from 15 organisations participated in the observational campaign. Several interesting results have emerged which will be published by scientists of participating agencies in the near future.

\section{Acknowledgement}

The support of Secretary, Department of Science and Technology (DST) in providing financial resources; Secretary, Department of Ocean Development (DOD) for the availability of ORV Sagar Kanya and MetOcean Buoys; and Director General of Meteorology, India Meteorological Department (IMD) for providing conventional and satellite weather observational systems is deeply acknowledged. Thanks are also due to the Director, Naval Physical Oceanography Laboratory, Kochi for the availability of the Ship Sagar Dwani. We are thankful to Prof. Sulochana Gadgil for her help in co-ordinating various resources. We are thankful to Dr. R K Midha, Dr. B D Acharya and Shri. D T Vengayil for their kind and helpful support at various stages of implementing the programme. Prof. G S Bhat of the IISc., Bangalore, Shri L V G Rao of NIO, Goa and Dr. K Gopal Reddy of Andhra University were Principal Investigators of the BOBMEX projects. These scientists are also thanked for their support in implementing the field phase of BOBMEX. We thank all the Chief Scientists and other participating scientists in the BOBMEX field phase.

\section{References}

DST (1996) The Indian Climate Research Programme- Science Plan, Govt. of India, New Delhi. 